Research Journal of Applied Sciences, Engineering and Technology 5(18): 4594-4606, 2013

DOI:10.19026/rjaset.5.4380

ISSN: 2040-7459; e-ISSN: 2040-7467

(C) 2013 Maxwell Scientific Publication Corp.

\begin{tabular}{lll}
\hline Submitted: January 16, 2013 & Accepted: February 18, 2013 & Published: May 05, 2013
\end{tabular}

\title{
Research Article Speed Control of Induction Motor Fed from Wind Turbine via Particle Swarm Optimization Based PI Controller
}

\author{
${ }^{1}$ A.S. Oshaba and ${ }^{2}$ E.S. Ali \\ ${ }^{1}$ Electronics Research Institute, Power Electronics and Energy Conversions, \\ NRC Blg., El-Tahrir St., Dokki, 12311-Giza, Egypt \\ ${ }^{2}$ Electric Power and Machine Department, Faculty of Engineering, Zagazig University, Zagazig, Egypt
}

\begin{abstract}
Three-phase Induction Motor (IM) is widely used in the industry because of its rugged construction and absence of brushes. However, speed control of IM is required depending on the desired speed and application. This study proposes a design of a Proportional Integral (PI) controller using Particle Swarm Optimization (PSO) algorithm to control the speed of an IM supplied from wind turbine. The wind turbine acts as a prime mover to a connected DC generator. Pulse Width Modulation (PWM) is used to obtain three phase AC voltage from the output of DC generator. The proposed design problem of speed controller is formulated as an optimization problem. PSO is employed to search for optimal controller parameters by minimizing the time domain objective function. The performance of the proposed technique has been evaluated with respect to the variation of load torque and speed wind turbine. Also the performance of the proposed controller has been evaluated with the performance of the PI controller tuned by Genetic Algorithm (GA) in order to demonstrate the superior efficiency of the proposed PSO in tuning PI controller. Simulation results emphasis on the better performance of the optimized PI controller based on PSO in compare to optimized PI controller based on GA over a wide range of load torque and speed wind turbine.
\end{abstract}

Keywords: DC Generator, Genetic Algorithm, Induction Motor, Particle Swarm Optimization, Pulse Width Modulation, Speed Control, Wind Turbine

\section{INTRODUCTION}

Nowadays, as a consequence of the important progress in power electronics and micro-computing, the control of AC electric machines has seen considerable development and the possibility for application (Hazzab et al., 2005). The Induction Motor (IM), known for its robustness, relatively low cost, reliability and efficiency, is the object of several research works. However its control presents difficulties because of its high non-linearity and its highly coupled structure (Mansouri et al., 2004).

Many intelligent approaches are used for speed control of IM such as Artificial Neural Network (ANN) (Zerikat and Chekroun, 2008; Dongale et al., 2012). The ANN approach has its own advantages and disadvantages. The performance of the system is improved by ANN based controller but, the main problem of these controllers are the long training time, the selecting number of layers and the number of neurons in each layer. Another artificial intelligence approach likes Fuzzy Logic Control (FLC) for designing adaptive speed control of IM is discussed in Fonseca et al. (1999), Chitra and Prabhakar (2006) and
Arulmozhiyal and Baskaran (2009) but a hard work is inevitable to get the effective signals when designing FLC. Also, it requires more fine tuning and simulation before operational.

Recently, global optimization techniques have attracted the attention in the field of controller parameter optimization (Fogel, 1995). These methods such as Tabu Search (TS) (Lee, 2005), Genetic Algorithms (GA) (Chebre et al., 2011) are used in speed control of IM. Despite these optimization methods seem to be effective for optimal location and setting of controller, the efficiency is reduced by the use of highly epi static objective functions (i.e., where parameters being optimized are highly correlated) and the large number of optimized parameters, then these methods have degraded effectiveness to obtain the global optimum solution. Further more, it is time consuming method.

Particle Swarm Optimization (PSO) is proposed as a solution to the above-mentioned problems and drawbacks. Swarming strategies in bird flocking and fish schooling are used in the PSO and introduced in Kennedy and Eberhart (1995) for optimal designing of controller parameters and defining its best location

Corresponding Author: E.S. Ali, Electric Power and Machine Department, Faculty of Engineering, Zagazig University, Zagazig, Egypt

This work is licensed under a Creative Commons Attribution 4.0 International License (URL: http://creativecommons.org/licenses/by/4.0/). 
(Abido, 2002; Panda and Padhy, 2008; Mostafa et al., 2012).

This study proposes the PSO for optimal designing of PI controller for speed control of IM fed by wind turbine, which has a simple structure and robust performance in a wide range of operating conditions. The design problem of the proposed controller is formulated as an optimization problem and PSO is employed to search for optimal controller parameters. By minimizing the time domain objective function, in which the deviations in error between the reference and actual speed is involved; speed control of IM is improved. Simulation results assure the effectiveness of the proposed controller in providing good speed control over a wide range of load torque and speed turbine. Also, these results validate the superiority of the proposed method in tuning controller compared with GA.

\section{SYSTEM UNDER STUDY}

The system under study consists of wind turbine acts as a prime mover to a connected DC generator. The DC output voltage is converted to three phase voltage through a Pulse Width Modulation (PWM). The three phase output voltage of PWM is fed to the three phase IM. The proposed controller based on PSO is used to control the speed of IM. The schematic block diagram is shown in Fig. 1.

IM model: The electrical part of IM is represented by a fourth-order state-space model and the mechanical part by a second-order model. All electrical variables and parameters are referred to the stator. This is indicated by the prime signs (") in the machine equation given below. All stator and rotor quantities are in the arbitrary

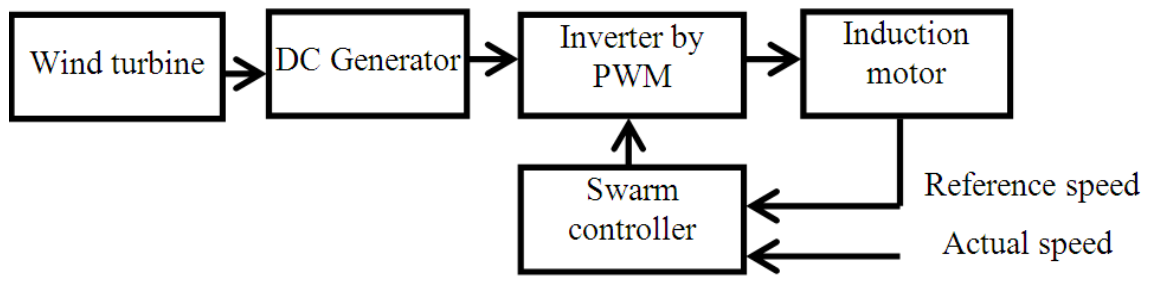

Fig. 1: The schematic block diagram of system under study

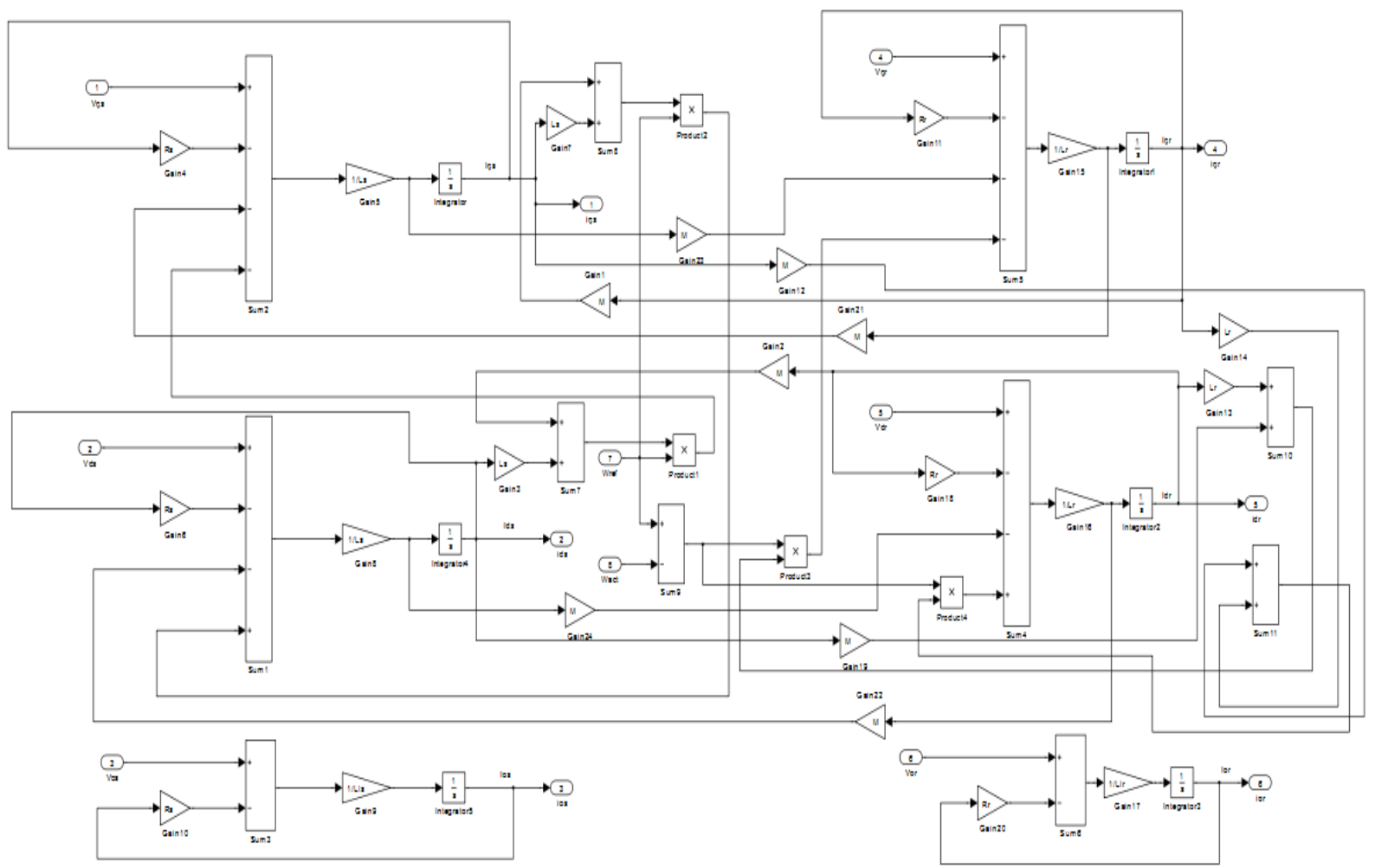

Fig. 2: The model of IM 
two-axis reference frame (q-d frame) (Fitgeraid et al., 1971; Krause, 1986; Bose, 2002). Figure 2 shows the Matlab/Simulink model of IM.

$$
\begin{aligned}
& V_{q s}=R_{s} i_{q s}+p \varphi_{q s}+\omega \varphi_{d s}, \quad V_{d s}=R_{s} i_{d s}+p \varphi_{d s}-\omega \varphi_{q s} \\
& V_{q r}^{\prime}=R_{r}^{\prime} i_{q r}^{\prime}+p \varphi_{q r}^{\prime}+\left(\omega-\omega_{r}\right) \varphi_{d r}^{\prime}, \quad V_{d r}^{\prime}=R_{r}^{\prime} i_{d r}^{\prime}+p \varphi_{d r}^{\prime}-\left(\omega-\omega_{r}\right) \varphi_{q r}^{\prime} \\
& T_{e}=1.5 P\left(\varphi_{d s} i_{q s}-\varphi_{q s} i_{d s}\right) \\
& \varphi_{q s}=L_{s} i_{q s}+L_{m} i_{q r}^{\prime}, \quad \varphi_{d s}=L_{s} i_{d s}+L_{m} i_{d r}^{\prime} \\
& \varphi_{q r}^{\prime}=L_{r}^{\prime} i_{q r}^{\prime}+L_{m}^{i} i_{q s}, \quad \varphi_{d r}^{\prime}=L_{r}^{\prime} i_{d r}^{\prime}+L_{m}^{i} d s \\
& L_{s}=L_{l s}+L_{m}, \quad L_{r}^{\prime}=L_{l r}^{\prime}+L_{m} \\
& \frac{d}{d t} \omega_{m}=\frac{1}{J}\left(T_{e}-B \omega_{m}-T_{L}\right) \\
& \frac{d}{d t} \theta_{m}=\omega_{m}
\end{aligned}
$$

where,

$R_{s}, L_{l s}=$ Stator resistance and leakage inductance

$R_{r}^{\prime}, L_{\mathrm{l} r}^{\prime}=$ Rotor resistance and leakage inductance

$L_{m} \quad=$ Magnetizing inductance

$L_{s}, L_{r}^{\prime} \quad=\quad$ Total stator and rotor inductances

$V_{q s}, i_{q s}=\mathrm{Q}$ axis stator voltage and current

$V_{q r}^{\prime}, I_{\mathrm{q} r}^{\prime}=\mathrm{Q}$ axis rotor voltage and current

$V_{d s}, i_{d s}=\mathrm{D}$ axis stator voltage and current

$V_{d r}^{\prime}, I_{\mathrm{d} r}^{\prime}=\mathrm{D}$ axis rotor voltage and current

$\varphi_{\mathrm{qs}}, \varphi_{\mathrm{ds}}=$ Stator $\mathrm{q}$ and $\mathrm{d}$ axis fluxes

$\varphi_{q r}^{\prime}, \varphi_{\mathrm{d} r}^{\prime}=$ Rotor $\mathrm{q}$ and $\mathrm{d}$ axis fluxes

$\omega_{m} \quad=$ Angular velocity of the rotor

$\theta_{m} \quad=$ Rotor angular position

$P \quad=\quad$ Number of pole pairs

$\omega_{r} \quad=$ Electrical angular velocity $\left(\omega_{m} * \mathrm{P}\right)$

$\theta_{r} \quad=$ Electrical rotor angular position $\left(\theta_{m} * \mathrm{P}\right)$

$T_{e} \quad=$ Electromagnetic torque

$T_{L} \quad=$ Shaft mechanical torque

$J \quad=$ Combined rotor and load inertia coefficient

$B=$ Combined rotor and load viscous friction coefficient

Dynamic Modeling of the Wind Turbine: The wind turbine is characterized by no dimensional curves of the power coefficient $(\mathrm{Cp})$ as a function of both the tip speed ratio $(\lambda)$ and the blade pitch angle $(\beta)$. In order to fully utilize the available wind energy, the value of $(\lambda)$ should be maintained at its optimum value. Therefore, the power coefficient corresponding to that value will become maximum also.

The model is based on the steady-state power characteristics of the turbine. The stiffness of the drive train is infinite and the friction factor and the inertia of the turbine must be combined with those of the generator coupled to the turbine (Heier, 1998).

The tip speed ratio $(\lambda)$ can be defined as the ratio of the angular rotor speed of the wind turbine to the linear wind speed at the tip of the blades. It can be expressed as follows:

$$
\lambda=\omega_{t} R / V_{\omega}
$$

where,

$R=$ the wind turbine rotor radius,

$V_{\omega}=$ the wind speed and $\omega_{\mathrm{t}}$ is the mechanical angular rotor speed of the wind turbine.

In addition to Eq. (9), the relation between $\lambda$ and $\beta$ can be found in the following relation (Heier, 1998):

$$
1 / \lambda_{i}=\frac{1}{\lambda+0.08 * \beta}-\frac{0.035}{\beta^{\wedge} 3+1}
$$

A generic equation is used to model $C_{p}(\lambda, \beta)$. This equation, based on the modeling turbine characteristics of Heier (1998), is:

$C_{p}(\lambda, \beta)=C_{1} *\left(C_{2} / \lambda_{i}-C_{3} * \beta-C_{4}\right) * e^{\wedge}\left(-C_{5} / \lambda_{i}\right)+C_{6} * \lambda$

where $\beta$ is the pitch angle and the coefficients $C_{1}$ to $C_{6}$ are:

$$
\begin{array}{lll}
\mathrm{C}_{1}=0.5176 & \mathrm{C}_{2}=116 & \mathrm{C}_{3}=0.4 \\
\mathrm{C}_{4}=5 & \mathrm{C}_{5}=21 & \mathrm{C}_{6}=0.0068
\end{array}
$$

The maximum value of $\mathrm{C}_{\mathrm{p}}$ characteristics $\left(\mathrm{C}_{\mathrm{p} \max }=\right.$ 0.48 ) is achieved for $\beta=0$ degree and for $\lambda=8.1$. This particular value of $\lambda$ is defined as the nominal value ( $\lambda$ nom).Wind turbine is designed to have low cut-in and cut out speed $(2-3 \mathrm{~m} / \mathrm{s}: 7-9 \mathrm{~m} / \mathrm{s})$. The power output equation of wind turbine can be described in Eq. (12):

$$
P_{t}=\frac{1}{2} \rho^{*} \Pi * C_{p} * V(\lambda, \beta)^{\wedge} 3 * R_{A} \wedge 2 / 735
$$

where,

$P_{t}=$ Wind power (hp)

$\rho=$ Air density $\left(\mathrm{kg} / \mathrm{m}^{3}\right)$

$V=$ Wind speed $(\mathrm{m} / \mathrm{s})$ 


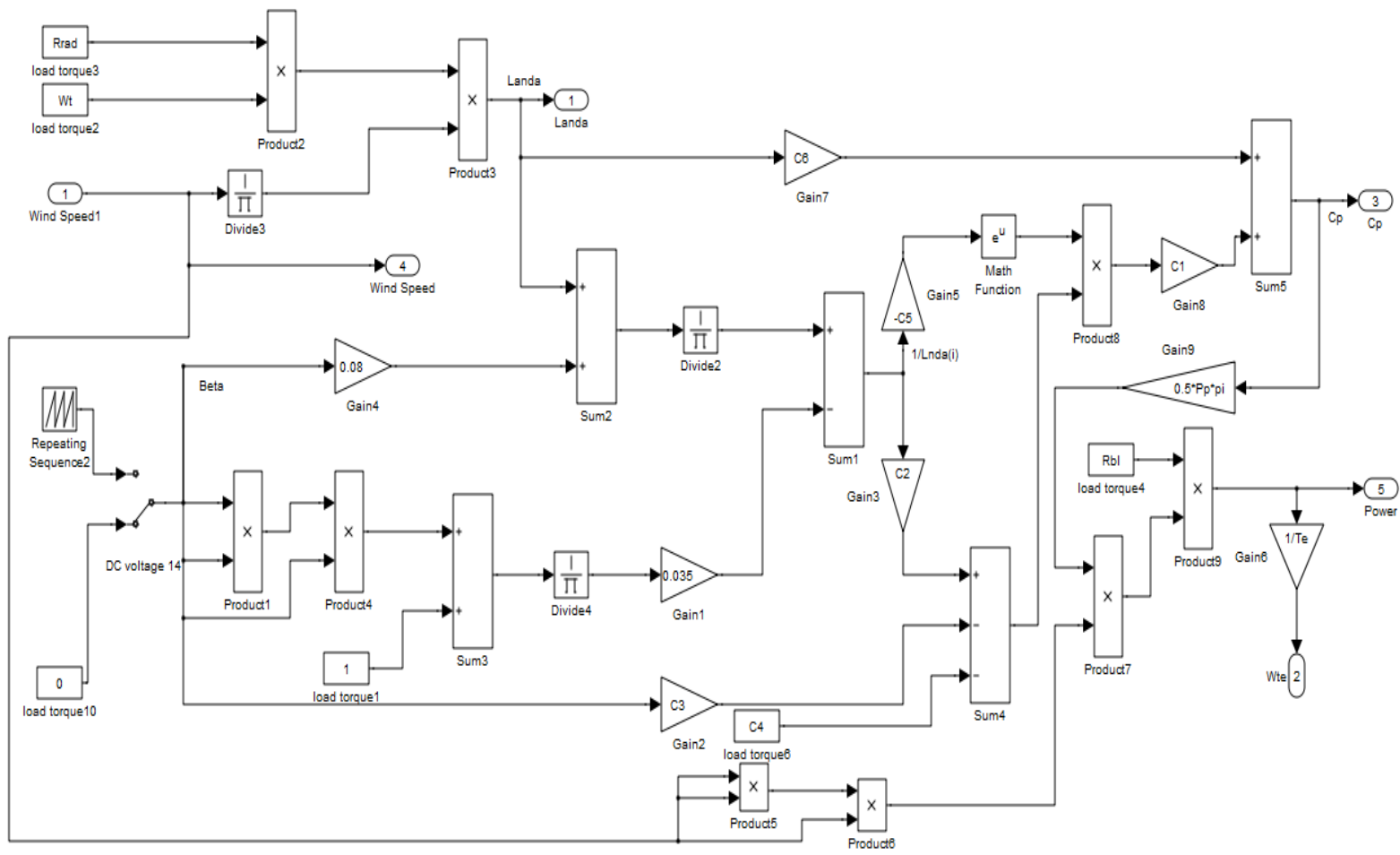

Fig. 3: The model of wind turbine

$R_{A}=$ The area of turbine blades $\left(\mathrm{m}^{2}\right)$

$C_{p}=$ Wind power coefficient turbine.

Figure 3 shows Matlab/Simulink model of the wind

DC Generator: The proposed system can be simulated with proper mathematic modeling. The DC generator can be written in terms of equations as follows (Krause, 1986; Bose, 2002). These nonlinear equations can be simulated using Matlab/Simulink in overall system:

$$
\begin{aligned}
& V_{f}=R_{f} * i_{f}+L_{f} \frac{d i_{f}(t)}{d t} \\
& i_{f} * \omega_{r} * M_{a f}=R * i_{a}+L \frac{d i_{a}(t)}{d t} \\
& V_{a}=R_{L} * i_{a}+L_{L} \frac{d i_{a}(t)}{d t}
\end{aligned}
$$

where,

$i_{a} \quad=$ The armature generator current

$V_{a} \quad=$ The armature generator terminal voltage

$i_{f} \quad=$ The field generator current

$V_{f} \quad=$ The field generator voltage

$R_{a}, L_{a}=$ The armature resistance and inductance

$R_{f}, L_{f}=$ The field resistance and inductance

$R_{L}, L_{L}=$ The load resistance and inductance

$$
\begin{array}{ll}
R & =\mathrm{R}_{\mathrm{a}}+\mathrm{R}_{\mathrm{L}} \\
L & =\mathrm{L}_{\mathrm{a}}+\mathrm{L}_{\mathrm{L}} \\
M_{a f} & =\text { The mutual inductance between stator and } \\
& \quad \text { rotor } \\
\omega_{r} \quad=\text { The input angular speed }
\end{array}
$$

\section{OBJECTIVE FUNCTION}

A performance index can be defined by the Integral of Time multiply Squared Error (ITSE). Accordingly, the objective function $\mathrm{J}$ is set to be:

$$
\mathrm{J}=\int_{0}^{\infty} t e^{2}(\mathrm{t}) \mathrm{dt}
$$

where,

$$
e=w_{\text {reference }}{ }^{-w_{\text {actual }}}
$$

Based on this objective function $\mathrm{J}$ optimization problem can be stated as: Minimize $\mathrm{J}$ subjected to:

$$
K_{p}^{\min } \leq K_{P} \leq K_{p}^{\max }, K_{i}^{\min } \leq K_{i} \leq K_{i}^{\max }
$$

This study focuses on optimal tuning of PI controller for speed tracking of IM motor using PSO 
algorithm. The aim of the optimization is to search for the optimum controller parameters setting that minimize the difference between reference speed and actual one. On the other hand, in this study the goal is speed control of IM motor and finally designing a loworder controller for easy implementation.

\section{OVERVIEW OF PSO AND GA OPTIMIZATION TECHNIQUE}

Particle Swarm Optimization (PSO): The PSO method is a member of wide category of Swarm Intelligence methods for solving the optimization problems. It is a population based search algorithm where each individual is referred to as particle and represents a candidate solution. Each particle in PSO flies through the search space with an adaptable velocity that is dynamically modified according to its own flying experience and also the flying experience of the other particles. In PSO each particles strive to improve themselves by imitating traits from their successful peers. Further, each particle has a memory and hence it is capable of remembering the best position in the search space ever visited by it. The position corresponding to the best fitness is known as pbest and the overall best out of all the particles in the population is called gbest (Kennedy and Eberhart, 1995; Abido, 2002).

The features of the searching procedure can be summarized as follows (Panda and Padhy, 2008):

- Initial positions of pbest and gbest are different. However, using the different direction of pbest and gbest, all agents gradually get close to the global optimum.

- The modified value of the agent position is continuous and the method can be applied to the continuous problem. However, the method can be applied to the discrete problem using grids for XY position and its velocity.

- There are no inconsistency in searching procedures even if continuous and discrete state variables are utilized with continuous axes and grids for XY positions and velocities. Namely, the method can be applied to mixed integer nonlinear optimization problems with continuous and discrete state variables naturally and easily.

- The above concept is explained using only XY axis (2 dimensional spaces). However, the method can be easily applied to $\mathrm{n}$ dimensional problem. The modified velocity and position of each particle can be calculated using the current velocity and the distance from the pbest $_{j, g}$ to gbest $_{g}$ as shown in the following formulas (Mostafa et al., 2012 ):

$$
\begin{gathered}
v_{j, g}^{(t+1)}=w^{*} v_{j, g}^{(t)}+c_{1}^{*} r_{1}()^{*}\left(\text { pbest }{ }_{j, g}-x_{j, g}^{(t)}\right)+c_{2} * r_{2}() *\left(\text { gbest }-x_{j, g}^{(t)}\right) \\
\left.x_{j, g}^{(t+1)}=x_{j, g}^{(t)}+v_{j, g}^{(t+1)}\right)
\end{gathered}
$$

with $j=1,2, \ldots, n$ and $g=1,2, \ldots, m$

where,

$n \quad=$ Number of particles in a group

$m=$ Number of members in a particle

$t=$ Number of iterations (generations)

$v_{j, g}^{(t)}=$ Velocity of particle $\mathrm{j}$ at iteration $\mathrm{t}$, with $v_{g}^{(\min )} \leq v_{j, g}^{(t)} \leq v_{g}^{\max } ;$

$w=$ Inertia weight factor

$c_{1}, c_{2}=$ Cognitive and social acceleration factors respectively

$r_{1}, r_{2}=$ Random numbers uniformly distributed in the range $(0,1)$

$x_{j, g}^{(t)}=$ Current position of $\mathrm{j}$ at iteration $\mathrm{t}$

pbest $_{j}=$ pbest of particle $\mathrm{j}$

gbest $=$ gbest of the group

The $j$-th particle in the swarm is represented by a $g$ dimensional vector $x_{j}=\left(x_{j, 1}, x_{j, 2}, \ldots \ldots ., x_{j, g}\right)$ and its rate of position change (velocity) is denoted by another $g$ dimensional vector $v_{j}=\left(v_{j, 1}, v_{j, 2}, \ldots \ldots ., v_{j, g}\right)$. The best previous position of the $j$-th particle is represented as pbest $_{j}=$ pbest $_{j, 1}$, pbest $_{j, 2}, \ldots \ldots$, pbest $_{j, g}$. The index of best particle among all of the particles in the group is represented by the gbest $_{g}$.

In PSO, each particle moves in the search space with a velocity according to its own previous best solution and its group's previous best solution. The velocity update in a PSO consists of three parts; namely momentum, cognitive and social parts. The balance among these parts determines the performance of a PSO algorithm. The parameters $c_{1} \& c_{2}$ determine the relative pull of pbest and gbest and the parameters $r_{1} \&$ $r_{2}$ help in stochastically varying these pulls.

In the above equations, superscripts denote the iteration number. Figure 4 shows the velocity and position updates of a particle for a two-dimensional parameter space. The computational flow chart of PSO algorithm is shown in Fig. 5. The parameters of PSO are shown in appendix.

Genetic Algorithm (GA): The GA has been used for optimizing the parameters of control system that are complex and difficult to solve by conventional optimization methods. GA maintains a set of candidate 


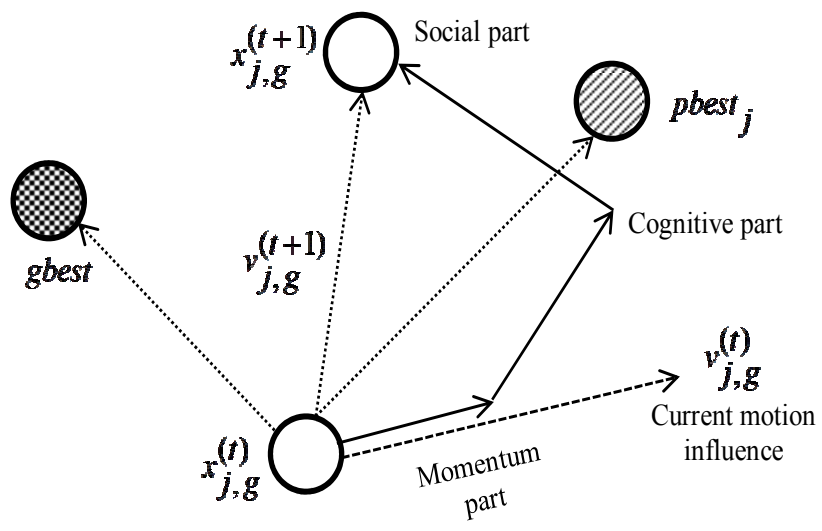

Fig. 4: Deception of velocity and position updates in PSO

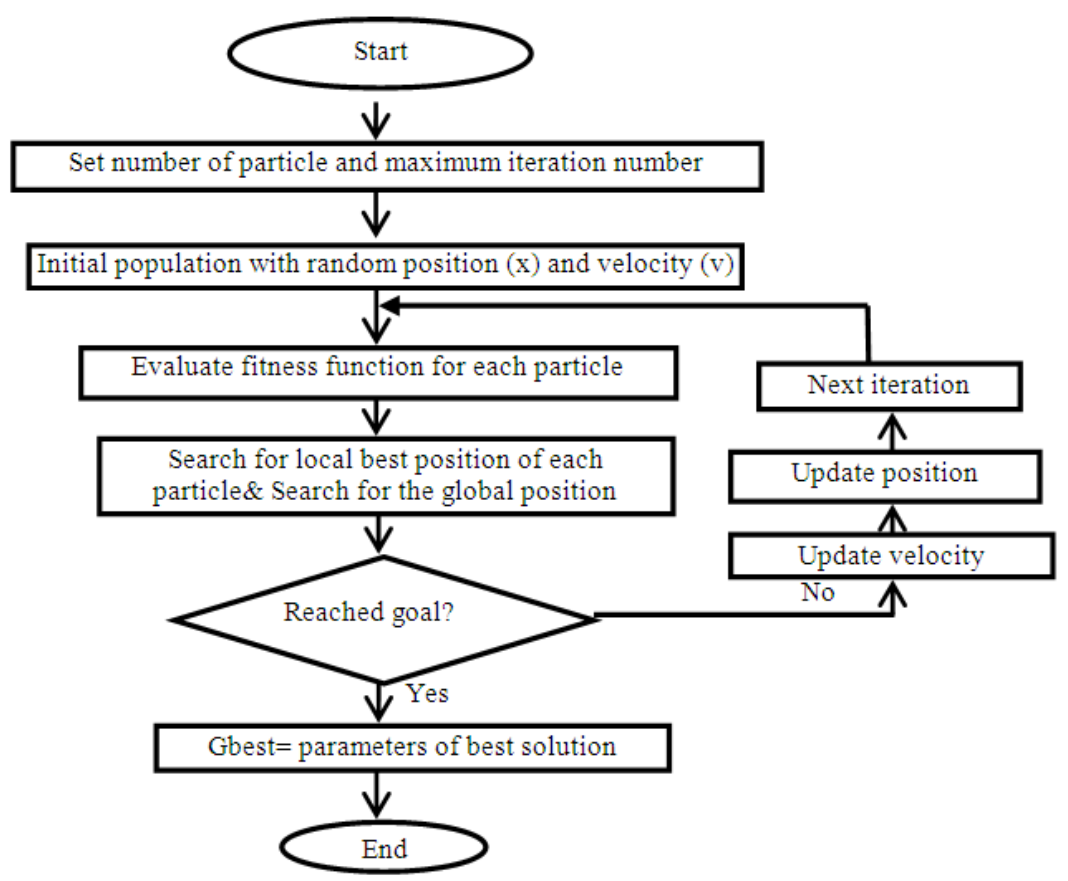

Fig. 5: Flow chart of PSO algorithm

solutions called population and repeatedly modifies them. At each step, the GA selects individuals from the current population to be parents and uses them produce the children for the next generation. Candidate solutions are usually represented as strings of fixed length, called chromosomes. A fitness or objective function is used to reflect the goodness of each member of population. Given a random initial population GA operates in cycles called generations, as follows (Goldberg, 1989):

- $\quad$ Each member of the population is evaluated using a fitness function.
- The population undergoes reproduction in a number of iterations. One or more parents are chosen stochastically, but strings with higher fitness values have higher probability of contributing an offspring.

- Genetic operators, such as crossover and mutation are applied to parents to produce offspring.

- The offspring are inserted into the population and the process is repeated.

The computational flow chart of GA is shown in Fig. 6. 


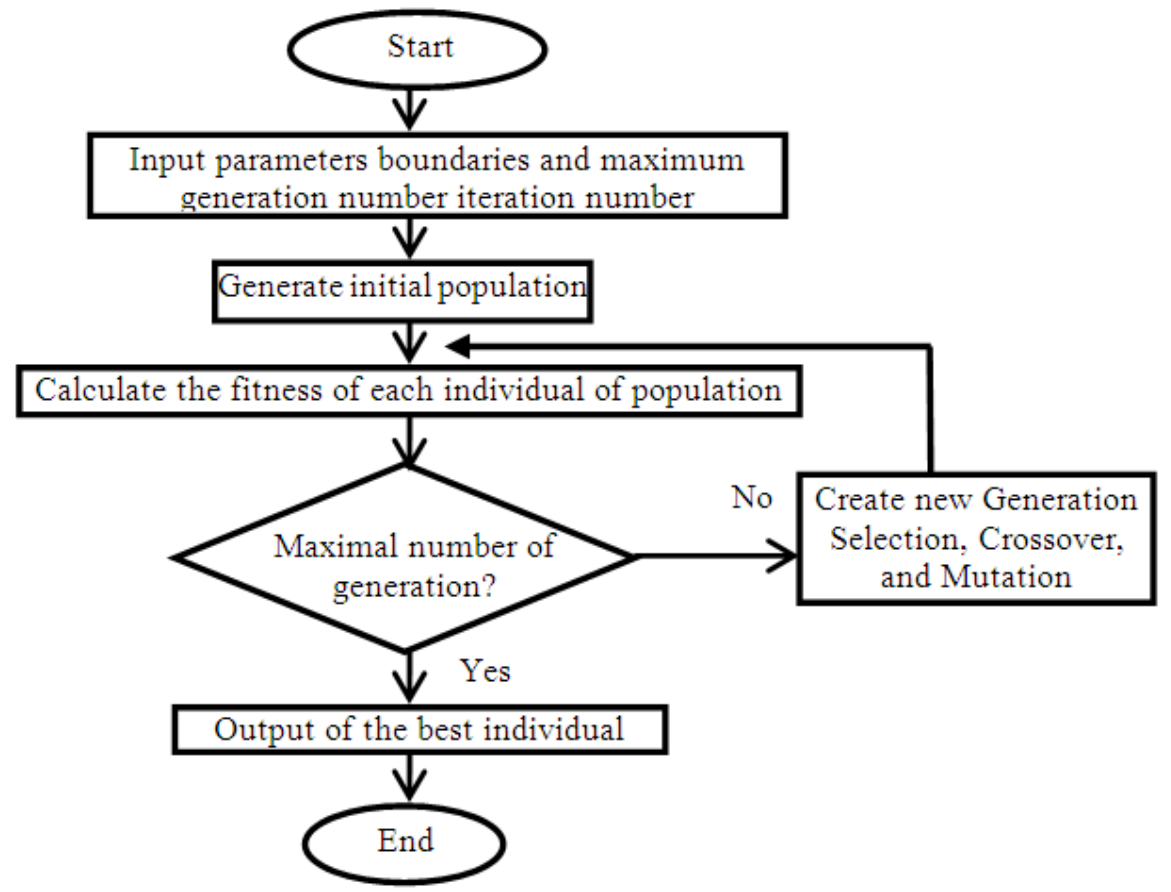

Fig. 6: Flow chart of GA algorithm

Table 1: The parameters of PI controller

\begin{tabular}{lll}
\hline & $\mathrm{GA}$ & $\mathrm{PSO}$ \\
\hline $\mathrm{K}_{\mathrm{P}}$ & 0.1348 & 0.1876 \\
$\mathrm{~K}_{\mathrm{i}}$ & 0.4285 & 0.7423 \\
\hline
\end{tabular}

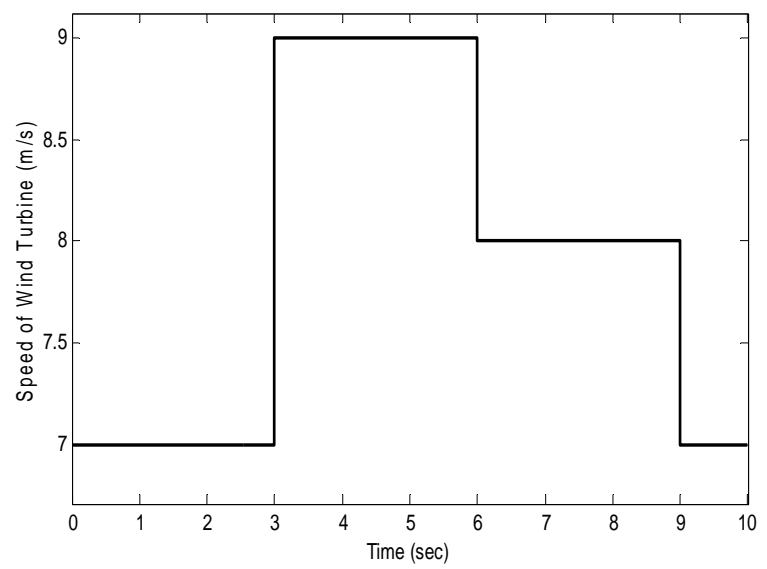

Fig. 7: The change of speed wind turbine

\section{RESULTS AND DISCUSSION}

In this section different comparative cases are examined to show the effectiveness of the proposed swarm speed controller for load torque and speed turbine variations. Table 1 shows the parameters of PI controller based on two optimization techniques.

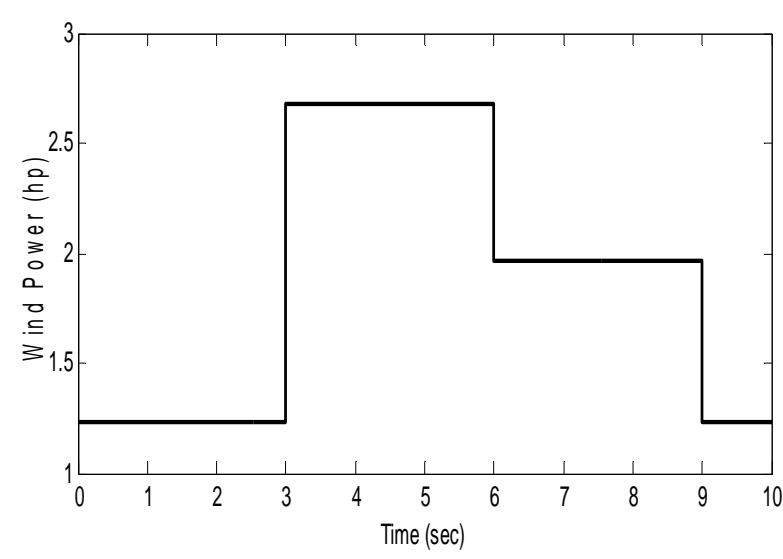

Fig. 8: The output power of wind turbine.

Response under variable wind turbine speed: As the first test case, the system responses under variation of the wind turbine speed are obtained. Figure 7 shows the variation of the speed wind turbine as an input disturbance while the load torque is constant at full load torque $(11.8$ N.m). Figure 8 shows the output power of the wind turbine. The output power is variable due to the change in wind speed. Figure 9a illustrates the output phase control voltage of PWM inverter by using the proposed controller while Fig. $9 \mathrm{~b}$ illustrates the zoom for phase voltage. Figure 10 and 11, show a comparison between the PSO and GA on the controller 
Res. J. Appl. Sci. Eng. Technol., 5(18): 4594-4606, 2013

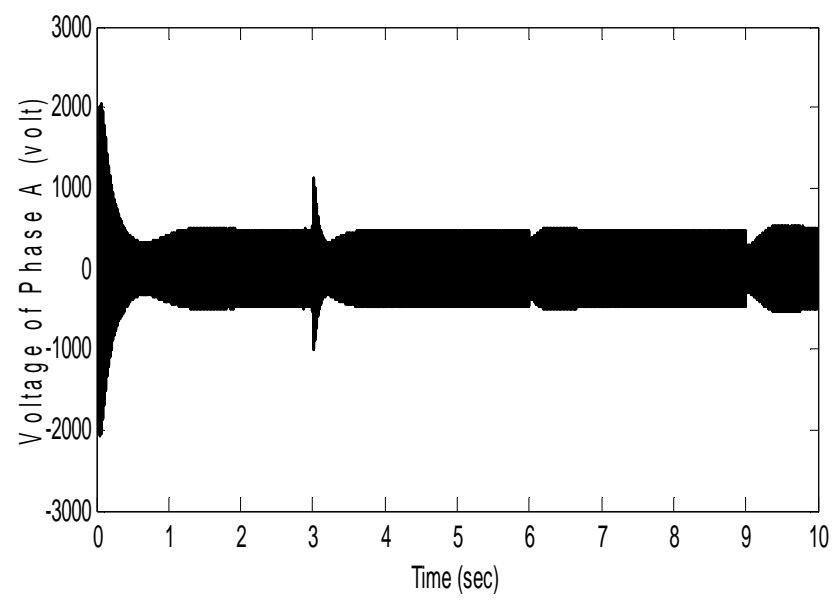

Fig. 9a: The output phase voltage of PWM inverter

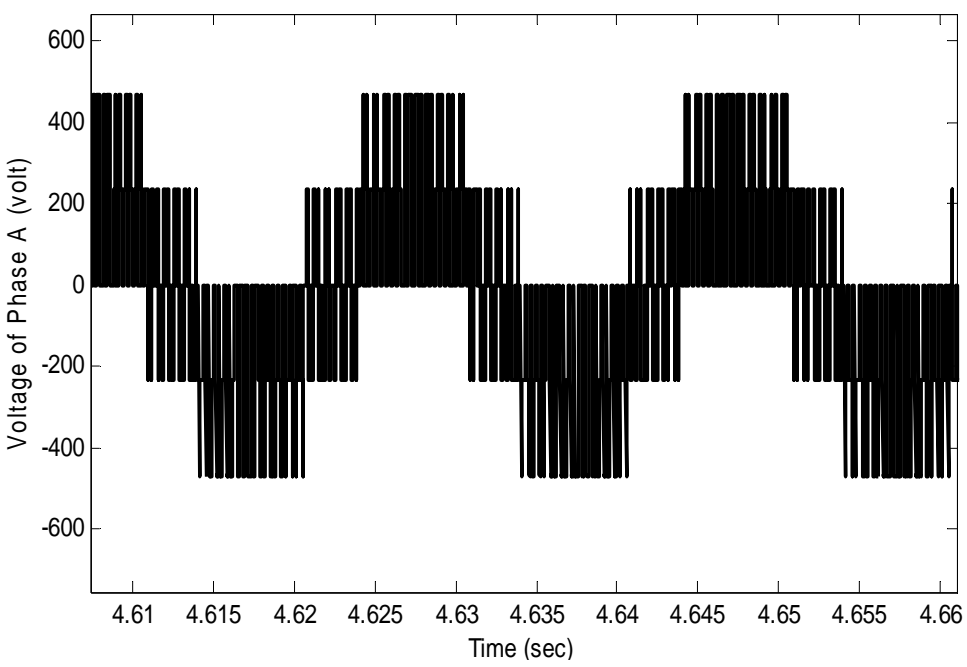

Fig. 9b: The zoom for output phase voltage of PWM inverter

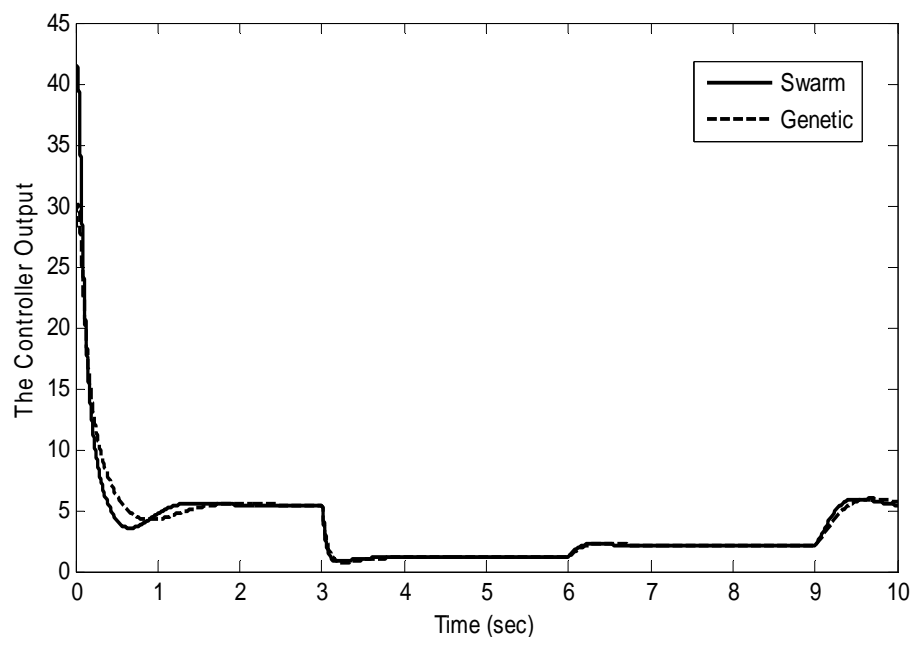

Fig. 10: The output controller signal for two controllers 
Res. J. Appl. Sci. Eng. Technol., 5(18): 4594-4606, 2013

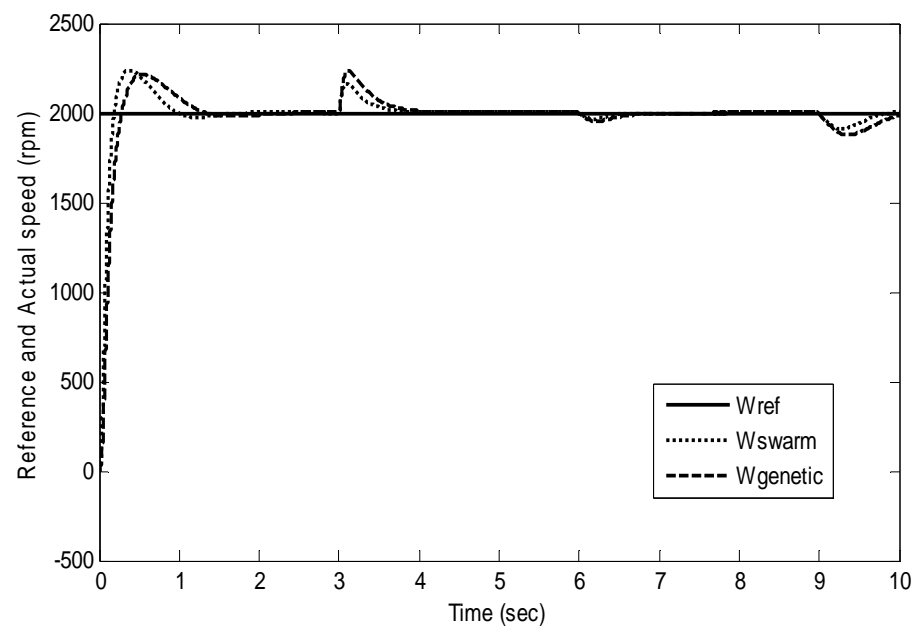

Fig. 11a: The response of IM speed under different controllers

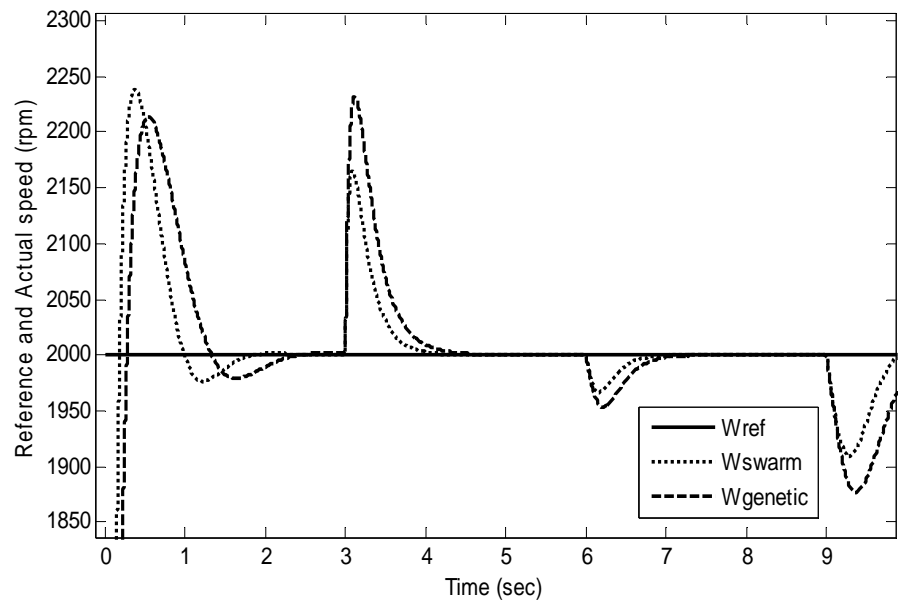

Fig. 11b: The zoom of IM speed under different controllers

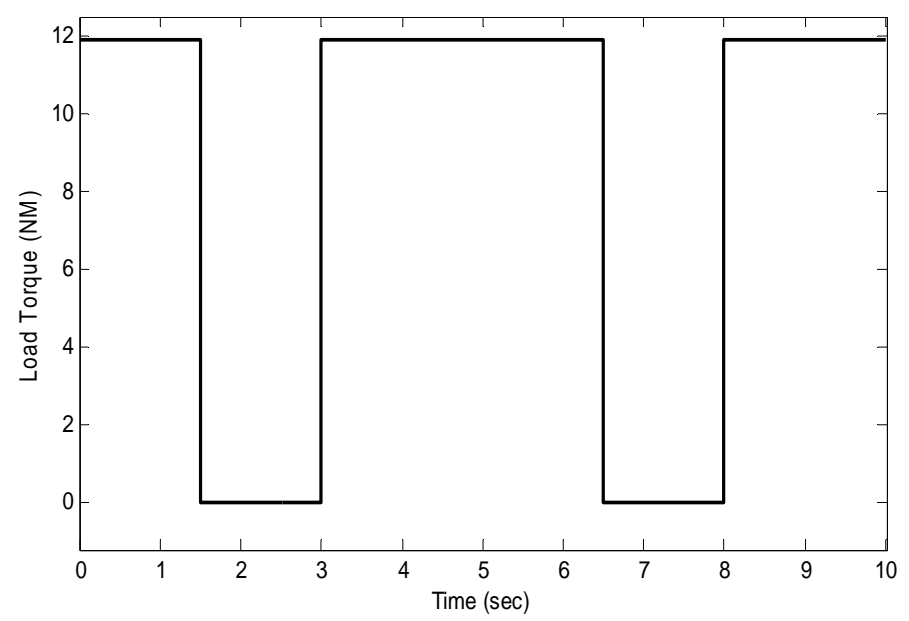

Fig. 12: The change of load torque 
Res. J. Appl. Sci. Eng. Technol., 5(18): 4594-4606, 2013

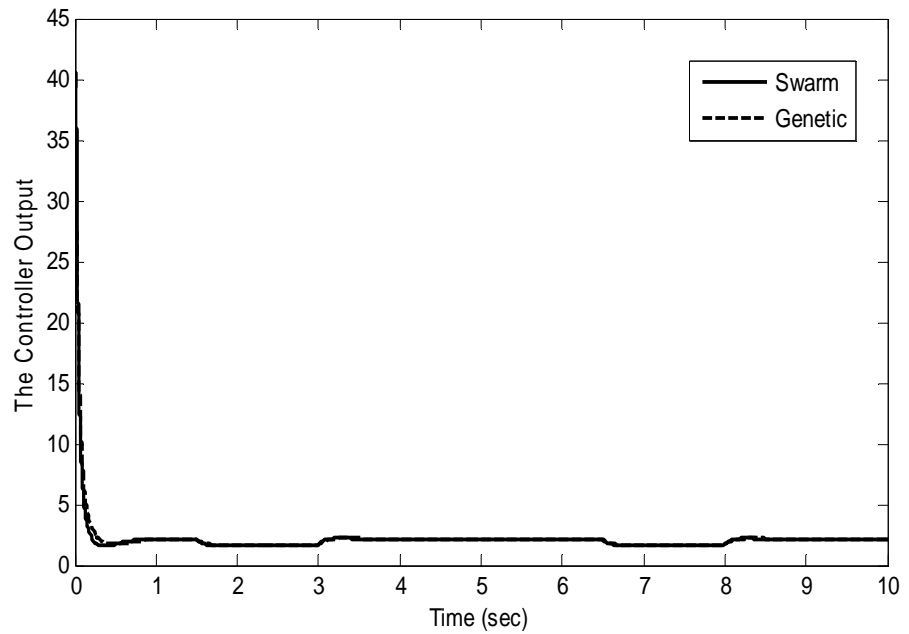

Fig. 13: The output controller signal for two controllers

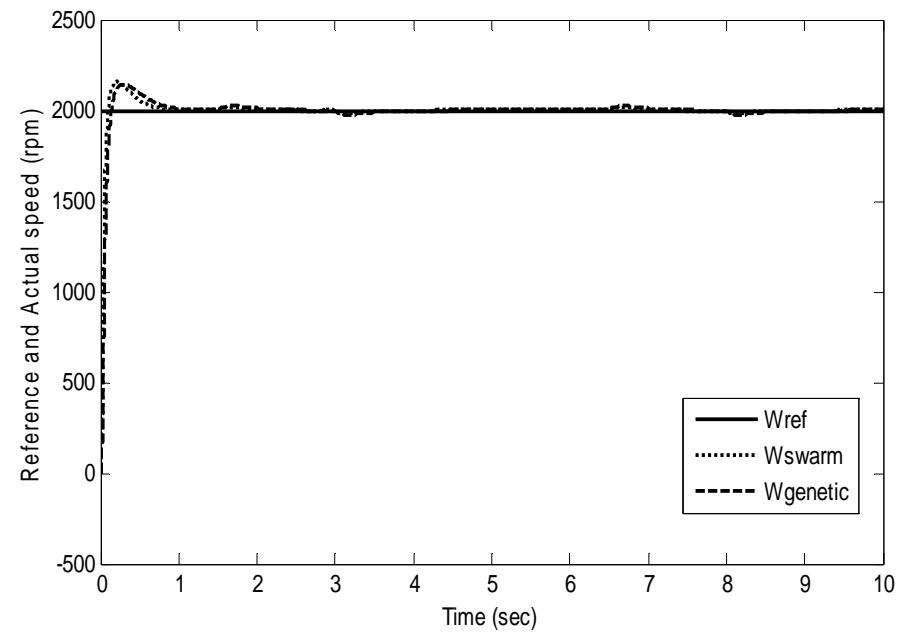

Fig. 14a: Speed response of IM for different controllers

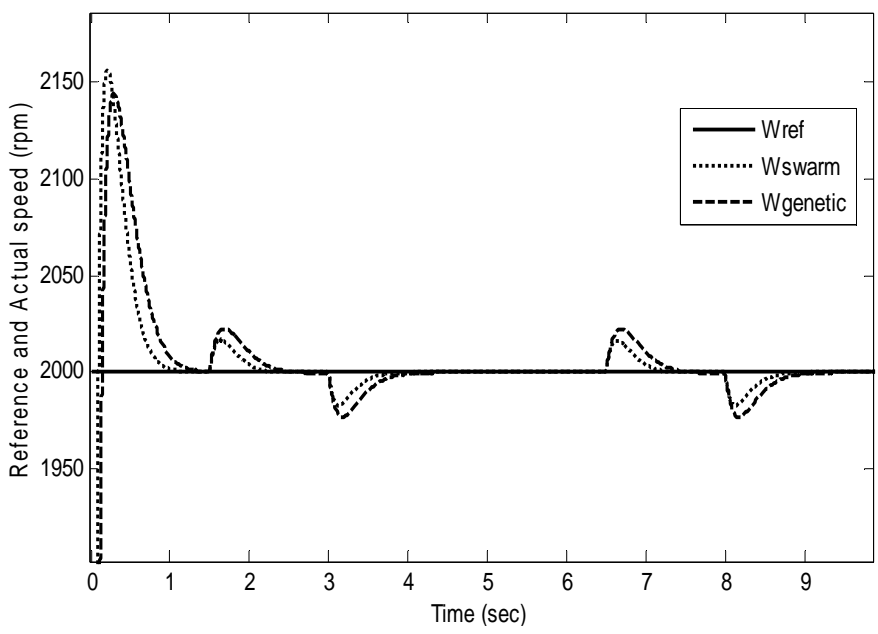

Fig. 14b: The zoom of speed response of IM for different controllers 
Res. J. Appl. Sci. Eng. Technol., 5(18): 4594-4606, 2013

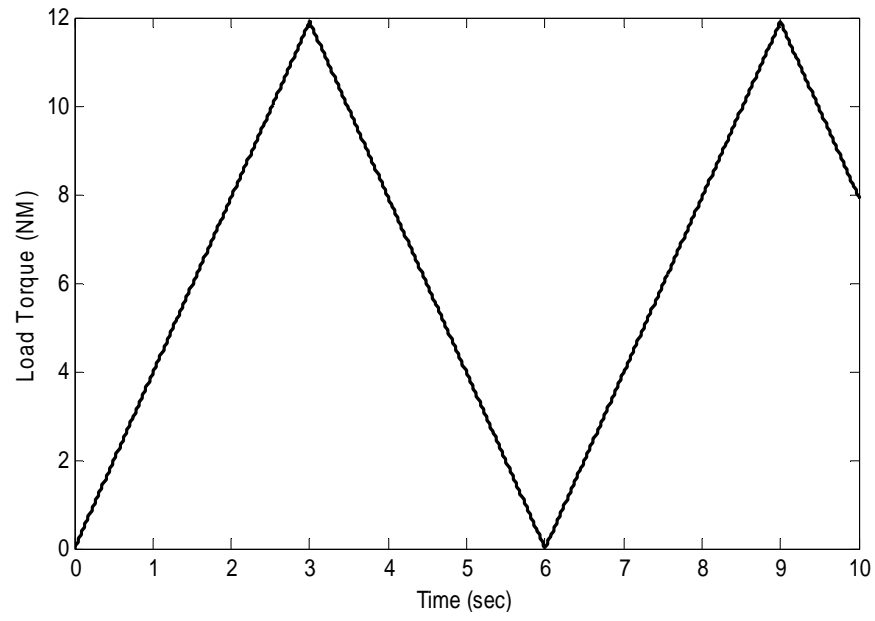

Fig. 15: The change of load torque

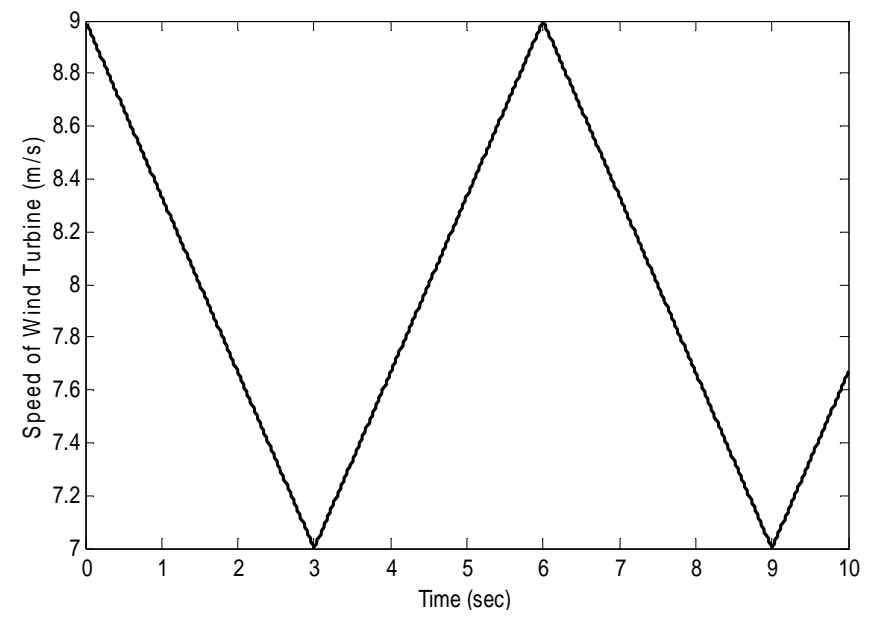

Fig. 16: The change of speed wind turbine

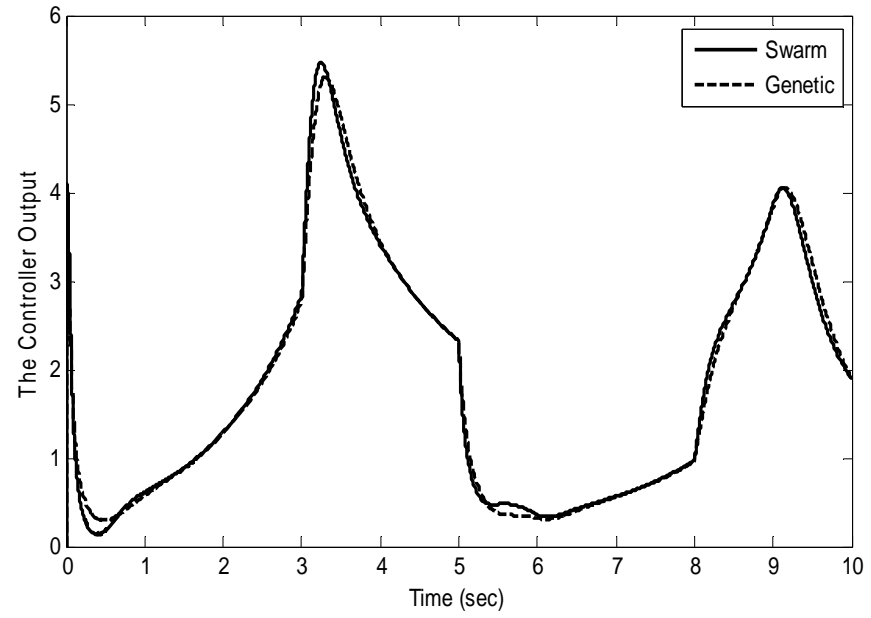

Fig. 17: The output controller signal for two controllers 
Res. J. Appl. Sci. Eng. Technol., 5(18): 4594-4606, 2013

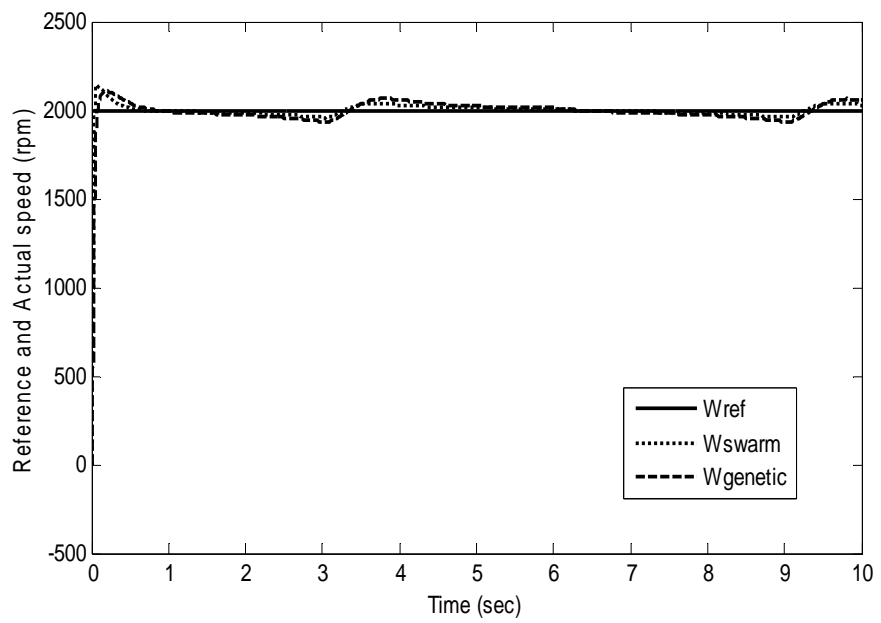

Fig. 18: The IM speed for different controllers

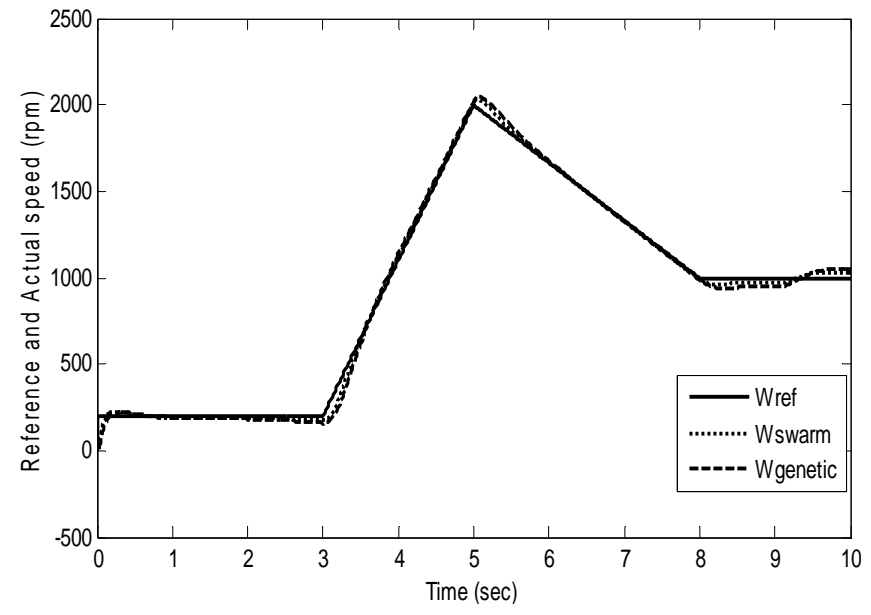

Fig. 19: The IM speed for both controllers under different reference speed

output signal and speed response of IM respectively. It is clear, the steady state and dynamic operation of IM in terms of over shoot and settling time has been enhanced. Moreover, the proposed controller is indeed more efficient in improving speed control of IM compared with GA.

Response under variable load torque: In this case, the system responses under variation of the load torque are obtained. Figure 12 shows the variation of the load torque as an input disturbance while the speed of wind turbine is constant at $8 \mathrm{~m} / \mathrm{s}$. Moreover, the system responses for different controllers are shown in Fig. 13 and 14. It is clear from these Figs. the proposed PSO controller outperforms and outlasts GA in controlling the speed of IM effectively and reducing settling time. Hence compared to the GA based controller, PI based PSO greatly enhances the system performance.
Response under variable load torque and wind turbine speed: In this case, variations of both load torque and speed wind turbine are applied. Figure 15 and 16 show the change of load torque and speed wind turbine respectively. Moreover, the system responses for both controllers are shown in Fig. 17 and 18. It is clear from these Figs, that the proposed controller is more efficient in improving speed control of IM compared with GA. Also, the proposed controller has a smaller settling time and system response is quickly driven with the reference speed. In addition, the superiority of the proposed controller compared with GA for tracking every change of reference speed is shown in Fig. 19. Hence, the potential and superiority of the proposed controller over the GA is demonstrated.

\section{CONCLUSION}

In this study, a novel method of speed controller of IM is proposed via PSO. The design problem of the 
proposed controllers is formulated as an optimization problem and PSO is employed to search for optimal parameters of PI controller. By minimizing the time domain objective function, in which the difference between the reference and actual speed are involved; speed control of IM motor is improved. Simulation results emphasis that the designed PSO tuning PI controller is robust in its operation and gives a superb performance for the change in load torque and speed wind turbine compared with GA tuning PI controller. Besides the simple architecture of the proposed controller, it has the potentiality of implementation in real time environment.

\section{APPENDIX}

The optimization parameters are as shown below:

- Genetic parameters: Max generation $=150$; Population size $=$ 50; Crossover probabilities $=0.75$; Mutation probabilities $=0.1$.

- $\quad$ PSO parameters: $c_{1}=c_{2}=2.0, \omega=0.9$.

\section{REFERENCES}

Abido, M.A., 2002. Optimal design of power system stabilizers using particle swarm optimization. IEEE T. Energ. Conver., 17(3): 406-413.

Arulmozhiyal, R. and K. Baskaran, 2009. Space vector pulse width modulation based speed control of induction motor using fuzzy PI controller. Int. J. Comput. Electr. Eng., 1(1): 98-103.

Bose, B.K., 2002. Modern Power Electronics and AC Drives. Prentice-Hall, New Jersey.

Chebre, M., A. Meroufel and Y. Bendaha, 2011. Speed control of induction motor using genetic algorithmbased PI controller. Acta Polytech. Hungar., 8(6): 141-153.

Chitra, V. and R.S. Prabhakar, 2006. Induction motor speed control using fuzzy logic controller. World Acad. Sci. Eng. Technol., 23: 17-22.

Dongale, T.D., T.G. Kulkarni, S.R. Jadhav, S.V. Kulkarni and R.R. Mudholkar, 2012. AC induction motor control: A neuro-fuzzy approach. Int. J. Eng. Sci. Adv. Technol., 2(4): 863-870.

Fitgeraid, A.E., C. Kingsiey and A. Kusko, 1971. Electric Machinery. 3rd Edn., McGraw -Hill Inc., NY.

Fogel, D.B., 1995. Evolutionary Computation toward a New Philosophy of Machine Intelligence. IEEE Press, New York.
Fonseca, J., J.L. Afonso, J.S. Martins and C. Couto, 1999. Fuzzy logic speed control of an induction motor. Microprocess. Microsyst., 22: 523-534.

Goldberg, D.E., 1989. Genetic Algorithms in Search, Optimization and Machine Learning. AddisonWesley, Reading, MA.

Hazzab, A., K. Bousserhane I, M. Kamli and M. Rahli, 2005. Design of fuzzy sliding mode controller by genetic algorithms for induction machine speed control. Proceeding of the 3rd IEEE International Conference on Systems, Signal and Devices (SSD’05), Tunisia.

Heier, S., 1998. Grid Integration of Wind Energy Conversion Systems. John Wiley and Sons Ltd., ISBN: 0-471-97143-X.

Kennedy, J. and R. Eberhart, 1995. Particle swarm optimization. Proceedings of IEEE International Conference on Neural Networks, pp: 1942-1948.

Krause, P.C., 1986. Analysis of Electric Machinery. McGraw-Hill, USA.

Lee, Y.W., 2005. A study on the design of speed controller for induction motor using tabu search algorithm. Science and Technology, 2005. Proceedings of the 9th Russian-Korean International Symposium on KORUS'2005, pp: 818-821.

Mansouri, A., M. Chenafa, A. Bouhenna and E. Etien, 2004. Power nonlinear observer associated with field-oriented control of an induction motor. Int. J. Appl. Math. Comput. Sci., 14(2): 209-220.

Mostafa, H.E., M.A. El-Sharkawy, A.A. Emary and K. Yassin, 2012. Design and allocation of power system stabilizers using the particle swarm optimization technique for an interconnected power system. Int. J. Electr. Power Energ. Syst., 34(1): 57-65.

Panda, S. and N.P. Padhy, 2008. Robust power system stabilizer design using particle swarm optimization technique. Int. J. Electr. Syst. Sci. Eng., 1(1): 1-8.

Zerikat, M. and S. Chekroun, 2008. Adaptation learning speed control for a high performance induction motor using neural networks. World Acad. Sci. Eng. Technol., 21: 293-298. 